\title{
PENERAPAN BERKUMUR MENGGUNAKAN LARUTAN MADU UNTUK MENGATASI MASALAH KEPERAWATAN KERUSAKAN MEMBRAN MUKOSA ORAL PADA PASIEN KANKER PAYUDARA
}

\author{
Dewi Damayanti, Zaira Chairunisa Ca Umar \\ Akademi Keperawatan Panca Bhakti Bandar Lampung \\ E-mail : dewi@pancabhakti.ac.id
}

\begin{abstract}
ABSTRAK
Salah satu efek samping dari kemoterapi yaitu mukositis. Mukositis merupakan inflamasi dan ulseri dari dinding mukosa pada mulut klien yang menerima terapi kanker. Mukositis menyebabkan pasien mengalami nyeri, penurunan nafsu makan dan keterlambatan kemoterapi. Penelitian ini bertujuan menganalisis efek penerapan berkumur larutan madu dalam menurunkan mukositis pada pasien kanker akibat kemoterapi. Metode dalam penelitian ini adalah metode terapan apllied research dengan desain penelitian One-Group Pretest-Postest Design. Teknik pemilihan sample pada penelitian ini menggunakan non probability sampling denganpendekatanpurposive. Dalam penelitian ini menggunakan instrument penelitian Oral Assessment Guide (OAG) untuk menilai skor mukositis. Pada peneitian ini menunjukan bahwa berkumur larutan madu dapat menurunkan skor mukositis pada kedua responden. Hasil penelitian berkumur larutan madu dapat dijadikansebagai salah satu penerapan untuk mengatasi mukositis pada pasien kanker payudara yang menjalanikemoterapi di RSAM Bandar Lampung. Rekomendasi untuk penelitian selanjutnya agar dilakukan penelitian dengan jumlah sample yang lebih banyak dana danya kelompok control dan kelompok yang diberi intervensi agar diperoleh hasil secara statistic dan lebih valid.
\end{abstract}

Katakunci: Berkumur larutan madu, Kanker payudara, Kemoterapi, Mukositis

\begin{abstract}
One of the side effects of chemotherapy is mucositis. Mucositis is an inflammation and ulceration of the mucous wall in the mouth of clients who receive cancer therapy. Mukositis causes patients to experience pain, decreased appetite and delay in chemotherapy. The aim of this study was to analyze the effect of applying gargling on a low solution in reducing mucositis in cancer patients due to chemotherapy. The method in this study is applied research with OneGroup Pretest-Postest Design. The sample selection technique in this study use non probability sampling with purposive approach. This study used the Oral Assessment Guide (OAG) research instrument to assess mucositis scores. This study showed that gargling of honey solution can decrease the mucositis score in both respondents. The results of gargling honey solution can be used as one application to overcome mukositis in breast cancer patients who underwent chemotherapy at RSAM Lampung Province. The recommendation for next researcher to conduct more sample size and the presence of control groups and groups who were given intervention to obtain statistical results and more valid.
\end{abstract}

Keywords: Breast cancer, Chemotherapy, Gargling honey solution, Mucositis 


\section{PENDAHULUAN}

Penyakit kanker salah satu penyebab kematian utama di seluruh dunia, sekitar 8,2 juta kematian disebabkan oleh kanker paru, hati, perut, kolorektal, dan kanker payudara (Globalcan, 2012). Kanker merupakan suatu kondisi dimana seltelah kehilangan pengendalian dan mekanisme normalnya, sehingga mengalami pertumbuhan yang tidak normal, cepat dan tidak terkendali. Kanker payudara merupakan penyakit dimana sel kanker yang ganas terdeteksi dalam jaringan payudara,sel - sel kanker ini kemudian menyebar di dalam jaringan atau organ tubuh dan kebagian tubuh yang lain (Kartikaswati, 2013).

Menurut data World Health Organization (WHO,2014) kasus kejadian penyakit kanker di seluruh dunia terus mengalami peningkatan yang signifikan. Kasus kanker pada tahun 2002 terdata 4,2 jutakasus, 12,7 juta kasus pada tahun 2008 dan pada tahun 2012 terjadi 14,1 kasus kanker baru, dengan 8,2 juta kematian akibat kanker dan 32,6 juta orang yang hidup dengn kanker. Menurut Global Burden Cancer (Globalcan, 2012) penyakit kanker merupakan salah satu penyebab kematian utama di seluruh dunia, sekitar 8,2 juta kematian disebabkan oleh kanker paru, hati, perut, kolorektal, dan kanker payudara. Kanker payudara merupakan penyakit kanker dengan persentase kasus baru tertinggi, yaitu sebesar 43,3\% dan persentase kematian akibat kanker payudara sebesar 12,9\%.Menurut data Riskesdas (2013) penyakit kanker pada penduduk semua umur di Indonesia adalahsebesar 1,4\% atau diperkirakan sekitar 342.792 penderita. Pada penyakit kanker payudara di Indonesia sebesar $0,5 \%$ atau diperkirakan sekitar 61.682 penderita., prevalensi kanker tertinggi diprovinsi Lampung penyakit kanker payudara sebesar 0,3\% atau 1.148 penderita. Dari data RSUD Abdul muluk didapatkan sejumlah 120 kasus dengan rincian 20 kasus $(16,5 \%)$ kanker payudara pada tahun 2009,7 kasus $(5,8 \%)$ kanker payudara pada tahun 2010, 25 kasus $(20,7 \%)$ padatahun 2012 dan semakin meningkat menjadi 49 kasus $(40,5 \%)$ kanker payudara pada 2013.

Pasien yang mengalami kanker akan mendapatkan pengobatan salah satunya Kemoterapi. Kemoterapi merupakan penggunaan obat antineoplastics sebagai upaya untuk membunuh sel - sel tumor dengan mengganggu fungsi dan reproduksi selular. Kemoterapi bertujuan untuk penyembuhan, pengontrol dan paliatif. Efek 
samping dari kemoterapi untuk kanker payudara yaitu mual, muntah, mucositis, keletihan, dermatitis, depresi sumsung tulang(Smeltzer and Bare, 2013).

Mukositis yaitu suatu lesi eritema dan ulseri di mukosa oral yang terjadi pada pasien dengan kanker yang menjalani kemoterapi di daerah yang berdekatan denganr ongga mulut (Taringan dan Wimardhani, 2010). Sekitar $40 \%$ darisemuapasienkanker yang menjalani kemoterapi mengalami mukositis, $75 \%$ pasien yang mengalami mukositis akibat kemoterapi mengalami komplikasi nyeri mulut. Nyeri yang dirasakan adalah nyeri sedang sampai berat. Bila gangguan ini tidak segera ditangani akan mengakibatkan gangguan lebihlanjut, yaitu gangguan keseimbangan nutrisi dan pada akhirnya mengakibatkan penurunan kualitas hidup pasien kanker (Simamoraet all, 2016)

$$
\begin{aligned}
& \text { Menurut Al Jaouniet all (2017), yang } \\
& \text { dilakukan di King Abdulaziz University } \\
& \text { Hospital dengan } 40 \text { repondem yang }
\end{aligned}
$$

mengalami mukositis oral yang dilakukan perawatan madu untuk mengurangi mukositis oral. Penelitian ini menunjukkan bahwa perlakuan madu topical efektif dalam mengurangi mukositis yaitu $(\mathrm{p}=0,02)$.

Menurut penelitian Simanoraet all (2016), yang dilakukan di RSUP H.Adam Malik dan RSUD DR.Pirngandi di Medan dengan 76 responden yang diberikan perawatan mulut menggunakan madu hasil penelitian menunjukkan ada pengaruh signifikan perawatan mulut menggunakan madu terhadap penurunan derajat mukositis yaitu harike III $(p=0,007)$ danharike VI $(p=0,000)$. Hal ini menunjukkan bahwa perawatan mulut yang dilakukan secara Teratur memberikan pengaruh positif terhadap penurunan derajat mukositis.

Menurut Sutari et all (2014), yang dilakukan di RSUP Sanglah dengan 24 responden yang mengalami disfungsi rongga mulut yang diberikan perawatan systemic oral care dengan madu. Menurut hasil uji statistic pengaruh systemic oral care dengan madu, 
dengan uji pairred sample t-test diperolehnilai $\mathrm{p}=0,000 \quad(\mathrm{p}<0,05)$, maka menunjukkan ada pengaruh signifikan systemic oral care dengan madu terhadap disfungsi rongga mulut akibat kemoterapi yaitu $\mathrm{p}=0,000(\mathrm{p}<0,05)$.

Madu sering digunakan dalam pengobatan modern karena memiliki efek terapeutik, yaitu memiliki ph rendah, mengandung zat antioksi dan, antiinflamasi, zat stimulant pertumbuhan, asam amino, vitamin, enzim, dan mineral (Bognadov, 2011). Dari teori yang dinyatakan bahwa larutan madu dapat menurunkan tindakan efektif untuk menurunkan mukositis pada pasien $\mathrm{Ca}$ mamae yang menjalani kemoterapi, maka penulis tertarik untuk menerapkan program tersebut pada pasien $\mathrm{Ca}$ mamae yang sedang menjalani pengobatan untuk kanker nyauntuk menurunkan derajat mukositis yang dialami pasien.

\section{METODOLOGI}

Metode penelitian ini menggunakanjenis motede penelitian terapan atau disebut dengan applied reseach. Penelitian terapan atau applied reseach bertujuan untuk menerapkan, menguji dan mengevaluasi kemampuan suatu teori, yang di terapkan dalam memecahkan masalah-masalah praktis (Sugiyono, 2013). Penerapan penelitian applied reseach umum nya mengunakan beberapa metode diantaranya metodee ksperimen dan survey karna dalam aplikasi pelaksanaannya peneliti mendapatkan data dari tempat-tempat tertentu yang alamiah (bukan buatan), peneliti melakukan perlakuan dalam mengumpulkan data dengan kuisoner, test dan wawancara terstruktur (Sugiyono, 2013).

Dipenelitian ini peneliti juga menganalisis treatment (perlakuan) tertentu pada responen penelitian applied reseach atau penelitian terapan juga bertujuan untuk menemukan pengetahuan yang secara praktis dapat diaplikasikan, walau punkadang penelitian terapanini juga mengembangkan dan menvalidasi suatu produk dalam penerapannya. Sampel tidak dipilih secara random dan tidak adanya variable kontrol. BentukPree -Eksperimen yang digunakana dalahOne-Grup Pretest-Posttest Design. 
Dalam penelitian ini sebelum perlakuan diberikan terlebih dahulu subjek di beripretest (tesawal) dan diakhiri perlakuan subjek diberi posttest (tesakhir). Desain ini digunakan sesuai dengan dengan tujuan yang hendak dicapai yaitu mengetahui dan mengevaluasi proses intervensi berkumur larutan madu apakah mampu mengatasi gangguan membran mukosa oral (mukositis oral) mukositis pada pasien kanker payudara yang menjalani kemoterapi. Berikut merupakan tabel DesainPenelitian One Grup Pretest Posttest Design (Sugiyono, 2013)

Tabel 1.

Rancangan penelitian One Group Posttest

Design padapasien kanker yang menjalani kemoterapi.

\begin{tabular}{ccc}
\hline Pretest & Perlakuan & Posttest \\
\hline 01 & $\mathrm{X}$ & 02 \\
\hline Pretest & Perlakuan & Posttest \\
\hline 01 & $\mathrm{X}$ & 02 \\
\hline
\end{tabular}

01 : Tes awal (pretest) skala mukositis sebelum diberikan

02 : Tesakhir (posttest) skala mukositis sesudah diberikan

Subjek dalam penerapan intervensi keperawatan umumnya pasien yang mengalami muksitis dengan jumlah minimal dua subjek. Hal ini didasarkan atas persyaratan dalam penyusunan karya tulis ini.
Subjek pada penelitian ini yaitu Asuhan Keperawatan Dengan Ca Mamae Yang Menjalani Kemoterapi Untuk Mengatasi Masalah Keperawatan Gangguan Membran Mukosa Oral (Mukositis Oral)Di Ruang Raflesia Rumah Sakit Abdul Moeloek Provinsi Lampung. Adapun kriteria inklusi partisipan yang dilibatkan pada penelitian ini adalah :

1. Pasien kooperatif, pasien kanker payudara yang menjalani kemoterapi 5 FU

2. Pasien termasuk dalam kategori mukositis primer yang ditandai dengan ulkus afrosa (sariawan)

3. Pasien dengan mukositis oral dengan stadium 2 dan 3

4. Pasien tidak memiliki komplikasi penyakit diabetes millitus (DM)

5. Pasien pada usia produktif $18-45$ tahun karena pasien lebih kooperatif

6. Pasien dengan kesadaran penuh

7. Pasien yang menjalani kemoterapi dengan diagnosa kanker payudara 
8. Mampu berbahasa Indonesia dengan baik dan berkomunikasi dengan jelas. Kemampuan partisipan dalam berbahasa Indonesia dan berkomunikasi dengan baik, akan memudahkan peneliti memahami maksud dan berkomunikasi dengan baik, akan memudahkan peneliti dalam memahami maksud yang disampaikan oleh responden

Adapun kriteria eksklusi dalam penelitian ini adalah pasien tidak kooperatif dan tidak bersedia menjadi responden. Teknik pemilihan sample pada penelitian

Ini menggunakan non probability sampling dengan pendekatan purposive atau teknik pengambilan sample dengan pertimbangan dan tujuan tertentu. Dalam penelitian ini pengambilan sample dengan menggunakan keseluruhan jumlah populasi yang ada.

\section{HASIL}

Berikut ini merupakanskor mukositis pada klien sebelum diberikan penerapan intervensi berkumur larutan maduyang dilakukan pengukuran (pre-test) 1 hari sebelum penerapan dilakukan menggunakan skala OAG (Oral Assessment Guide) yaitu pada tanggal 28 Mei 2018 dan 30 mei 2018:

Tabel 2.

Hasil Skor Mukositis Dengan Skala OAG (Oral Assessment Guide) Pada Responden Sebelum DilakukanPenerapan Intervensi Berkumur Larutan MaduDi Ruang Raflesia Di RSUD Abdoel Moeloek Provinsi LampungPada Tahun 2018 (n2)

\begin{tabular}{cccc}
\hline No & $\begin{array}{c}\text { Nama } \\
\text { Responden }\end{array}$ & $\begin{array}{c}\text { Skor } \\
\text { Mukositis }\end{array}$ & Keterangan \\
\hline 1 & Ny. P & 14 & $\begin{array}{c}\text { Derajat } \\
\text { Mukositis } \\
\text { Sedang }\end{array}$ \\
\hline 2 & Ny. M & 13 & $\begin{array}{c}\text { Derajat } \\
\text { Mukositis } \\
\text { Sedang }\end{array}$ \\
\hline
\end{tabular}

Menurut data diatas sebelum dilakukan inervensi berkumur larutan madu untuk menurunkan kerusakan membran mukosa oral (mukositis oral) pada pasien kanker payudara yang menjalani pengobatan kemoterapi didapatkan bahwa klien berada dalam derajat mukositis sedang, hal ini dapat dilihat dari rentang nilai yang didapatkan yaitu 9 16.Skor untuk klien pertama yaitu 14 dan klien kedua dengan skor 13.Berikut ini merupakanskor mukositis pada klien sesudah diberikan penerapan intervensi berkumur larutan madu: 
Tabel 3.

Hasil Skor Mukositis Dengan Skala OAG (Oral Assessment Guide) Pada Responden SesudahDilakukan Penerapan Intervensi Berkumur Larutan Madu Di Ruang Raflesia Di RSUD Abdoel Moeloek Provinsi Lampung Pada Tahun 2018 (n2)

\begin{tabular}{cccc}
\hline No & $\begin{array}{c}\text { Nama } \\
\text { Responden }\end{array}$ & $\begin{array}{c}\text { Skor } \\
\text { Mukositis }\end{array}$ & Keterangan \\
\hline 1 & Ny. P & 12 & $\begin{array}{c}\text { Derajat } \\
\text { Mukositis } \\
\text { Sedang }\end{array}$ \\
\hline 2 & Ny. M & 11 & $\begin{array}{c}\text { Derajat } \\
\text { Mukositis } \\
\end{array}$ \\
& & Sedang \\
\hline
\end{tabular}

Menurut data diatas sesudah dilakukan penerapan berkumur larutan madu untuk menurunkan kerusakan membran mukosa oral (mukositis oral) pada pasien kanker payudara yang menjalani pengobatan kemoterapi selama 3 hari didapatkan bahwa hasill penilaian pada Ny. P skor mukositis 12 sedangakan Ny. M skor mukositis 11.

Berikut ini merupakan perbandingan skor mukositis pada klien sebelum dan sesudah diberikan penerapan intervensi berkumur larutan madu:

Tabel 4.

Perbandingan Hasil Skor Mukositis Sebelum dan Sesudah Dengan Skala OAG (Oral Assessment Guide) Pada responden Sebelum dan Sesudah Dilakukan Penerapan Intervensi

Berkumur Larutan Madu Di Ruang Raflesia

Di RSUD Abdoel Moeloek Provinsi

Lampung pada tahun 2018 (n2)

\begin{tabular}{cccc}
\hline No & $\begin{array}{c}\text { Nama } \\
\text { Responden }\end{array}$ & Sebelum & Sesudah \\
\hline 1 & Ny. P & 14 & 12 \\
\hline 2 & Ny. M & 13 & 11 \\
\hline
\end{tabular}

\section{PEMBAHASAN}

Pada penelitian ini penulis akan menjelaskan hasil observasi penerapan intervensi dibandingkan dengan tinjauan teori dan evidence basedyang dapat menjawab tujuan khusus pada penelitian ini.

\section{Karakteristk Responden}

Dilihat dari karakteristik responden pada penelitian iniNy. P berada pada usia 39 tahun dan Ny. M pada usia 43 tahun sehingga dilihat dari rata - rata kedua responden berada pada rentang usia > 39 tahun. Dilihat dari jenis kelamin kedua responden sama - sama berjenis kelamin perempuan, Pendidikan pada Ny. P SD sedangkan Ny. M SMA, keduanya sama-sama beragama Islam. Pada kedua responden mengalami kanker payudara stadium 3 B, dan menjalani kemoterapi 
neoadjuvant dengan tujuan untuk mengecilkan tumor sebelum dilakukan pembedahan.

Usia klien merupakan usia dengan prevalensi insidensi kejadian kanker payudara tertinggi. Menurut Firasi dan Yudhanto(2013) wanita diatas usia 35 tahun yang memiliki resiko lebih tinggi terjadinya kanker payudara. Semakin tinggi usia, semakin tinggi resiko terkena kanker payudara. Selain itu, pada wanita diatas 40 tahun terutama yang masih mengalami masa reproduksi, setiap bulan akan mengalami menstruasi, namun tidak mengalami ovulasi, sehingga hormon progesteron yang dihasilkan tidak cukup menangkal hormon estrogen yang merupakan pemicu terjadinya kanker payudara.

Kedua responden berjenis kelamin perempuan, kanker payudara tidak hanya diderita wanita, namun bisa saja diderita kaum laki - laki. Di dunia, kanker payudara dialami oleh $99 \%$ wanita dan $1 \%$ laki - laki (devina et all, 2015).

Menurut Suyatno dan Pasaribu (2010) jenisjenis kemoterapi ada 3 yaitu kemoterapi

adjuvant, kemoterapi neoadjuvant dan kemoterapi primer. Kemoterapi adjuvant merupakan terapi tambahan setelah terapi utama (pembedahan).Tujuannya adalah untuk mendapatkan penyembuhan yang sempurna (kuratifitas) dan memperlama timbulnya metastasis.Adjuvant kemoterapi menurunkan 25\% mortalitas kanker payudara.Kemoterapi Neoadjuvant merupakan pemberian kemoterapi pada penderita kanker dengan high grade malignancy dan belum pernah mendapat tindakan loco-regional dengan bedah atau radiasi. Tujuannya untuk memperkecil ukuran tumor (shrinkage tumor) dan kontrol mikrometastasis, disamping itu neoadjuvant dapat memberikan informasi tentang respon regimen kemoterapi. Kemoterapi primer (paliatif) diberikan pada stadium lanjut (stadium IV), untuk mengendalikan gejala yang ditimbulkan oleh penyakit kanker. Tujuannya adalah untuk mempertahankan kualitas hidup yang baik, kontrol progresi tumor, dan memperlama harapan hidup. 
Faktor resiko terjadinya kanker payudara diantaranya meliputi adanya riwayat kanker payudara pada keluarga, obesitas, kebiasaan merokok, konsumsi alkohol, pemakaian alat kontrasepsi hormonal dalam jangka waktu yang lama, paparan radiasi, tidak pernah melahirkan atau melahirkan anak pertama pada usia lebih dari 35 tahun, serta tidak menyusui, menopause yang terlambat, yaitu pada usia $>50$ tahun, dan mengalami menstrusi pertama pada usia $<12$ tahun (Depkes RI, 2014). Sedangkan menurut (Housseinzadeh et all, 2014) faktor resiko kanker lebih besar disebabkan oleh faktor lingkungan dibandingkan dengan faktor genetik. Faktor - faktor kejadian kanker adalah genetik (5-10\%), dan (90-95\%) disebabkan faktor lingkungan termasuk pola makan 30-35\%, merokok $25-30 \%$ dan konsumsi alkohol 4-6\% (Suyanto \& Pasaribu, 2014). Jadi menurut data - data diatas faktor lingkungan dan gaya hidup yang dapat memicu terbesar kanker payudara.

Kurangnya aktifitas fisik dan gaya hidup yang tidak sehat dalam kehidupan sehari - hari dapat meningkatkan resiko kejadian kanker payudara terutama yang memiliki riwayat kanker pada keluarga. Adanya hubungan antara riwayat keluarga dengan kanker payudara disebabkan karena riwayat keluarga atau keturunan memungkinkan akan terjadi generasi keturunan saat ini ataupun berikutnya dan kadang timbulnya secara tiba - tiba tanpa gejala sehingga penanganan yang diberikan terlambat (Nasution. et all, 2018).

Pada penelitian ini faktor yang berhubungan dengan resiko kanker payudarapada responden Ny. P klien pernah menjalani terapi hormonal, Ny. $\mathrm{P}$ memiliki riwayat $\mathrm{KB}$ hormonal selama 10 tahun dengan jenis pil. Pada responden Ny. M sedang menjalani KB hormonal selama 7 tahun dengan jenis suntik. Kedua responden memiliki riwayat penggunaan terapi hormonal jangka panjang yaitu diatas 5 tahunMenurut (Nasution. et all, 2018) penggunaan kontrasepsi hormonal yang terlalu lama dapat mengacaukan keseimbangan hormon estrogen dalam tubuh sehingga mengakibatkan sel yang normal menjadi tidak normal. Dari faktor diatas 
faktor yang tidak berhubungan pada pada Ny.P yaitutidak pernah merokok dan minum - minuman alkohol, didalam keluarga juga tidak ada yang menderita penyakit kanker payudara, klien pertama kali menstuasi pada umur 15 tahunmelahirkan anak pertama pada usia lebih dari 23 tahun. Klien menyusui anak nya, klien juga tidak memiliki riwayat tumor jinak dan kanker sebelumnya. Sedangkan pada Ny. M klien tidak merokok, minumminuman alkohol, menstruasi pertama umur 14 tahun, keluarga klien tidak ada yang menderita kanker payudara, melahirkan anak pertama pada usia 21 tahun, klien menyusui anaknya, kien juga tidak memiliki riwayat tumor jinak dan kanker sebelumnya.

\section{Penerapan Intervensi Berkumur Larutan}

\section{Madu}

Menurut Black dan Hawks (2014)salah satu efek samping dari kemoterapi yaitu mukositis. Mukositis merupakan inflamasi dan ulseri dari dinding mukosa pada mulut, inflamasi yang terlihat di mulut juga terdapat sepanjang saluran pencernaan dari klien yang menerima terapi kanker.Mukositis dapat menyebabkan pasien mengalami nyeri, penurunan konsumsi nutrisi dan cairan, infeksi, malabsorpsi, diare, keterlambatan kemoterapi.

Pada penelitian ini kedua responden menggunakan agen kemoterapi 5-FU yang dapat memicu terjadinya mukositis.Obat kemoterapi seperti 5-FU memiliki resiko tinggi terhadap kejadian mukositis (20\%50\%), mukositis merupakan dampak buruk utama dari pemberian terapi jenis infuse intravena 5-FU terutama diberikan bersaman dengan leucovorin.Lesi oral yang diakibatkan dapat membuat pasien nyeri sehinga merasa tidak nyaman yang akhirnya berdampak pada penurunan intake nutrisi serta berefek pada penurunan kualitas hidup pasien juga.

Pada penelitian ini kedua responden mengalami mukositis pada seminggu setelah kemoterapi.Menurut (Tarigan dan Wimardhani, 2010) Mukositis oral yang terjadi akibat kemoterapi biasanya terjadi pada mukosa berkeratin tipis seperti pada leteral lidah, mukosa bukal dan palatum 
lunak. Ulseri biasanya muncul dalam 2 minggu awal dimulainya kemoterapi

Hasil penelitian pada Ny. P mengatakan menderita mukositis setelah dilakukan kemoterapi pertama kali jadi klien sudah mengalami mukositis selama 2 minggu dan klien mengatakan selama menderita mukositis nafsu makan klien menurun dikarenakan nyeri saat mengunyah dan menelan. dan Ny. M mengatakan menderita mukositis setelah menjalani kemoterapi yang kedua kali.Klien mengatakan nafsu makan klien menurun setelah mengalami mukositis tersebut. Menurut (Simamora et all, 2016) sekitar 40\% dari semua pasien kanker yang menjalani kemoterapi mengalami mukositis, $75 \%$ pasien yang mengalami mukositis akibat kemoterapi mengalami komplikasi nyeri mulut. Nyeri yang dirasakan adalah nyeri sedang sampai berat. Bila gangguan ini tidak segera ditangani akan mengakibatkan gangguan lebih lanjut, yaitu gangguan keseimbangan nutrisi dan pada akhirnya mengakibatkan penurunan kualitas hidup pasien kanker. Sehingga jika mukositis pada klien dibiarkan secara terus menerus dapat menurunkan berat badan klien menurun dan dapat menghambat proses kemoterapi.

Berdasarkan hasil penelitian didapati skala mukositis sebelum dilakukan intervensi berkumur larutan madu untuk menurunkan mukositis pada pasien kanker payudara yang menjalani kemoterapi pada $\mathrm{Ny}$. P yaitu derajat sedang dengan skor 14 dan Ny. M yaitu derajat sedang dengan skor mukostis 13 , hal ini dapat dilihat dari rentang nilai yang didapati 9-16 mukositis sedang. Setelah dilakukan intervensi berkumur larutan madu pada Ny. P dan Ny. M selama 3 hari dan dievaluasi didapati penurunan skor mukositisyaitu pada Ny. P 12 (derajat mukositis sedang) dan Ny. M skor mukositis 11(derajat mukositis sedang).Hal ini sesuai dengan penelitian yang dilakukan oleh Nurhidayahet all, (2013) yaitu rata - rata pasien yang menjalani kemoterapi menderita mukositis dengan skor mukositis diatas 12 .

Pada Ny. P saat hari pertama setelah dilakukan pemberian intervensi berkumur larutan madu skor mukositis 14 (derajat 
mukositis sedang) sedangkan pada hari ketigasetelah dilakukan pemberian intervensi berkumur larutan madu klien mengalami penurunan skor mukositis menjadi 12, ( derajat mukositis sedang).Pada Ny. M saat hari pertama setelah dilakukan pemberian intervensi berkumur larutan madu skor mukositis 13 (derajat mukositis sedang) sedangkan pada hari ketiga setelah dilakukan pemeberian intervensi berkumur larutan madu klien mengalami penurunan skor mukositis menjadi 11 ( derajat mukositis sedang),yang berarti kedua responden mengalami penurunan skor mukositis tetapi masih tetap pada kategori stadium mukositis sedang. Hal ini sesuai dengan penelitian yang dilakukan (Nurhidayatun, 2012) yang mengatakan tidak ada perbedaan pada perubahan stadium mukositis antara hari pertama dan hari ketiga dilakukan intervensi.

Madu mengandung berbagai jenis komponen kimia dan mirobiologis yang dapat digunakan dalam penyembuhan luka.Kandungan glukosa, fruktosa dan sukros berfungsi meningkatkan tekanan osmotik.Kadar osmotik yang tinggi dalam madu menyebabkan madu mampu mengekstrak dan mengabsorpsi air dari sel bakteri sehigga bakteri kehilangan banyak air dan metabolismenya terganggu. Akibatnya pertumbuhan bakteri terhenti dan akhirnya bakteri akan mati. Ph madu yang asam berfungsi menghambat pertumbuhan bakteri dengan menciptakan lingkungan asam pada luka sehingga mencegah bakteri melakukan penetrasi dan kolonisasi (Iqbal, 2008 dalam Simamora et all, 2016).

Hasil penelitian ini sesuai dengan penelitian Simamora et all (2016) perawatan mulut menggunakan madu menunjukkan pengaruh yang signifikan dalam penurunan derajat mukositis pada hari ke 3 dan ke 6 jika dilakukan secara teratur. Madu lebih efektif menurunkan derajat mukositis sebesar 4.662 kali dibandingkan dengan chlorhexidine 0,2 persen. Dari hasil penelitian didapatkan hasil skor mukositis pada klien kanker payudara yang menjalani pengobatan kemoterapi terjadi perubahan yang cukup bermakna setelah 
dilakukan pemberian intervensi berkumur larutan madu.Maka dari itu peneliti berpendapat bahwa berkumur larutan madu mempunyai efek untuk menurunkan skor mukositis pada pasien kanker payudara yang menjalani kemoterapi.

\section{KESIMPULAN}

Skor mukositis pada kedua responden yang menjalani kemoterapi sebelum diberikan intervensi berkumur larutan madu berada pada kategori mukositismukositis sedang ,hal ini dapat dilihat dari rentang nilai yang didapatkan yaitu 9 - 16. Skor ukositisuntuk Ny. P yaitu 14 dan Ny. M dengan skor 13.

Skor mukositis pada kedua responden yang menjalani kemoterapi setalah diberikan in tervensi berkumur larutan madu mengalami penurunan skor mukositis yaitu Ny. P 12 danskormukositis Ny. M yaitu 11 tetapi masih dalam rentang kategori mukositis sedang.Terdapat penurunan skormukositis pada kedua responden setelah diberikan intervensi berkumur larutan madu.

\section{KEPUSTAKAAN}

Al Jaouni, et all. 2017. Effects Of Honey On Oral Mucositis Among Pediatric Cancer Patients Undergoing Chemo/Radiotherapy Treatment At King Adbulaziz University Hospital In Jeddah, Kingdom of Saudi Arabia.Hindawi Evidence-base Complementary And Alternative Medicine volume 2017, Article ID 5861024, $\quad 7$ pages http://doi.org/10.1155/2017/5861024

BOGDANOV, S. (2011) Honey as Nutrient and Functional Food: A Review[WWW]. Diambil dari: http://www.beebexagon.net/files/file/fileE/HealthHoney/ 8HoneyNutrientFunctionalReview.pdf [Diakses: 6 Januari 2017].

Black J dan Hawks J. 2014.Keperawatan Medikal Bedah, Manajement Klinis untuk Hasil yang Diharapkan.Edisi 8. BukuPertama.Elsevier. Singapore.

Black J dan Hawks J. 2014.Keperawatan MedikalBedah, Manajement Klinisuntuk Hasil yang Diharapkan.Edisi 8.Buku Kedua.Elsevier. Singapore.

Depkes RI. 2014. Buku Saku Pencegahan KankerLeher Rahim Dan Kanker Payudara. Jakarta.

Dewi G Dan Hendrati L. 2015. Analisis Risiko Kanker Payudara Berdasarkan Riwayat Pemakaian Kontrasepsi Hormonal Dan Usia Menarche. Jurnal Berkala Epidemiologi 3 (1). 12 - 23.

Devina et all. 2015. Psychological Well Being Pada Wanita Penderita Kanker Payudara Yang Telah Melakukan Masektomi. Jurnal Psibernetika 8 (1).76-90.

Firasi A Dan Yudhanto E. 2016. Hubungan usiaterhadap derajat diferensiasi kanker payu dara pada wanita. Jurnal kedokterandiponegoro5 (4). 327- 336. 
Globocan. 2012. Estimated Cancer Incidence, Mortality,Prevalence and Disabilityadjusted life years (DALYs) Worldwide in 2008. IARC Cancer Base No. 11. Diakses tanggal 28 Desember 2018 time 8.50.

Hosseinzadeh et all. 2014. Risk Factors For Breast Cancer In Iranian Women. Journal Of Breast Cancer 17 (3). 236 $-245$.

WHO. World Health Statistics 2014: World Health Organization; 2014.

Kartikawati, E. 2013. Awas!!! Bahaya Kanker Payudara \& Kanker Serviks. Bandung : Buku Baru

Nasution et all. 2018. Pengaruh Pemakaian Kontrasepsi Hormonal Dan Riwayat Keluarga Terhadap Kejadian Kanker Payudara. Jurnal Medika Respati 13 (2). $39-47$.

Nurhidayatun, 2012. Uji Klinis Randomisasi: Pengaruh Perawatan Mulut Menggunakan Madu Terhadap Perubahan Stadium Mukositis Pada Anak Kanker Di Rs Kanker Dharmais Jakarta. Thesis. Program S2 Megister Ilmu Keperawatan Peminatan Anak Fakultas Ilmu Keperawatan Universitas Indonesia (UI).Depok.

Nurhidayah, R.E. Tarigan, R \& Nurbaiti. (2014). Latihan Range Of Motion (ROM).Medan : Fakultas Keperawatan USU

Sugiyono. 2010. Metode Penelitian Kualitatif dan R\&D.Bandung: ALFABETA.

Sutari, M., Abdalrahim, MS., Hamdanmansour, AM., \& Ayasrah,SM. (2014). Pain among mechanically ventilated patients in critical care units. Journal of Research in Medical Science

Suyatno, Pasaribu E.T., 2014. Kanker Payudara. Dalam : Bedah Onkologi Diagnosis dan Terapi Edisi 2. Sagung Seto Jakarta
Tarigan \& Wardani (2012). Low Lavel Laser Therapy For Threatment Of Oral Mucositis. Jounal Of Dentistry. Indonesia. Volume 17 93-100 